\title{
REPRESENTAÇÕES IMAGÉTICAS DO FAZER CIENTÍFICO NO CONTEXTO DO INSTITUTO NACIONAL DO CINEMA EDUCATIVO
}

\author{
Carmen Irene C. de Oliveira*
}

RESUMO: Considera a divulgação científica como ponto central no desenvolvimento da educação científica. Focaliza o Instituto Nacional de Cinema Educativo (Ince) e o ideário da Escola Nova com relação ao uso de filmes em processos educativos. Analisa o filme $O$ oxigênio para subsidiar a discussão, delineando as representações ligadas ao fazer científico. O filme apresenta três partes harmônicas: a) contextualização: apresentação genérica da substância; b) segmento experimental: espaço do laboratório e dos experimentos; c) consolidação: destaque para a presença da substância oxigênio em diferentes instâncias, inclusive a militar. Considerando uma nova concepção de processo educativo, à época, destacam-se, das análises: a percepção da Física com sua estrutura experimental e o uso do laboratório; a ideia de aceleração nos campos sociais e econômicos, levando à sensação de transformação; a divulgação científica sendo focalizada como elemento principal nos processos de educação científica.

Palavras-chave: Divulgação científica. Educação científica. Ince. Filme.

\footnotetext{
Departamento de Ciências Sociais da Universidade Federal do Estado do Rio de Janeiro (Unirio). Rio de Janeiro (RJ) - Brasil.

Contato com a autora: <irenecor2004@gmail.com>
} 
Representaçôes imagéticas do fazer científico no contexto do Instituto Nacional...

\title{
IMAGETIC REPRESENTATIONS OF SCIENTIFIC WORK IN THE CONTEXT OF THE NATIONAL INSTITUTE OF EDUCATIONAL CINEMA
}

\begin{abstract}
Considering the popularization of science as a central point in the development of Science education we focus on the $\mathrm{Na}$ tional Institute of Educational Cinema (Instituto Nacional de Cinema Educativo - Ince) and the ideals of the Escola Nova regarding the use of films in educational processes. The discussion is supported by the analysis of the film Oxygen, which reveals the representations related to scientific production. The film features three harmonic parts: a) context: general presentation of the substance, b) the experimental segment: the lab and experiments space and c) consolidation: highlighting the presence of the substance oxygen in different applications, including military ones. Considering a new conception of the educational process we emphasize: the perception of Physics with its experimental structure and laboratory use, the idea of accelerating social and economics fields leading to a feeling of transformation and the disclosure of scientific findings as the main element in the processes of science education.
\end{abstract}

Key words: Popularization of science. Science education. Ince. Film.

\section{Introdução}

ciência, na contemporaneidade, tornou-se a base do conhecimento
para a ação de boa parte da população mundial, fato, como diria
Capria (2004), com o qual podemos concordar plenamente ou com restrições, mas não podemos negar. Como afirma o autor, há um grande número de publicações que dão conta de temáticas que outrora a ciência nunca teria se ocupado, como, por exemplo, "Deus e a nova física", "Teorias sobre tudo" e "A física da imortalidade". O desenvolvimento científico transformou mentalidades, visões de mundo, práticas educacionais e passou a funcionar como sistema explicativo dos fenômenos. Essa trajetória envolveu um alto grau de especialização que trouxe consequências para as sociedades científicas, que se transformaram em grupos de eruditos; para as revistas que começaram, também, a se especializar; e para a linguagem que os cientistas utilizavam para comunicar suas descobertas. Em pouco tempo, a divulgação da ciência tinha dois objetivos: adaptação para os leigos e informação para os cientistas de uma área que tivessem interesse em outra (MORA, 2003, p. 23). Contemporaneamente, a questão que se coloca é como as descobertas 
científicas podem chegar ao conhecimento não somente dos decisores, como também do cidadão, aquele que, em virtude das grandes mudanças que o binômio ciência-tecnologia introduziu na sociedade, deve ser esclarecido sobre as consequências desse processo.

Em paralelo, mas com uma história mais recente, a questão da imagem em movimento tem sido problematizada por diferentes áreas e a partir de diferentes perspectivas: estéticas, econômicas, políticas, sociais, ideológicas e educacionais. Há uma enorme variedade de estudos brasileiros e estrangeiros que dão conta da relação educação e cinema, tomando filmes documentários, ficcionais, educativos, entre outros, seja a partir do seu contexto de produção, seja considerando unicamente os recursos da linguagem cinematográfica.

O cinema como marco da Modernidade é perspectivado em função do seu impacto não somente na visualidade, mas, também, nas formas de representação do real (fenômeno que acompanha, também, a fotografia) e nos modos de recepção e construção de subjetividades.

O que deve ser ressaltado é que o cinema nasce em estreita ligação com as ciências, e os primeiros registros da imagem em movimento causaram impacto positivo em vários cientistas, que viam no filme o seu potencial científico para observação, visualização, análise, compreensão e comunicação de suas descobertas. Dois exemplos: Eugène-Louis Doyen (1859-1916), famoso cirurgião francês que, desde as primeiras apresentaçôes públicas dos filmes dos irmãos Lumière, aderiu ao uso desse meio. De suas iniciativas, derivou-se o que seria a primeira projeção oficial de filmes cirúrgicos na França. Já em 1889, ele formou uma equipe composta por dois cinematografistas, tornando-se um dos precursores da filmografia cirúrgica, a partir da difusão das técnicas que desenvolveu (LEFBVRE, 1994). ${ }^{1}$ Jean Comandon (1877-1970), com a sua "cinematografia do invisível", desenvolveu um microcinematógrafo e dedicouse a uma produção que ilustra a articulação entre cinema e ciência com filmes de investigação, de ensino e de popularização cientifica (O'GOMES, 1994).

Educação, ciência e cinema. Em nossas investigações, consideramos que tal relação, articulada a uma cultura científica, não é um fenômeno recente e tem raízes na visão cientificista que marcou a Modernidade. Especificamente para este artigo, temos como perspectiva o contexto brasileiro, tomando a divulgação científica como ponto central no desenvolvimento de uma cultura que tem a educação científica como correlato, focalizando o contexto de criação do Instituto Nacional de Cinema Educativo (Ince) e ressaltando o ideário da Escola Nova com relação ao uso de filmes em 
Representaçôes imagéticas do fazer científico no contexto do Instituto Nacional...

processos educativos. A análise do filme $O$ oxigênio, produzido no âmbito do Instituto e cuja classificação é de divulgação, funciona para subsidiar a discussão, delineando as representações ligadas ao fazer científico, ao espaço do laboratório e aos avanços tecnológicos e industriais do Brasil, indo além da ação de difundir a ciência.

\section{A produção fílmica e a divulgação científica no contexto do Ince}

Observamos que alfabetização científica, educação científica e cultura científica encontram-se no centro de debates que investem nas questôes educacionais e informacionais, tendo em vista não somente o esclarecimento, mas, sobretudo, a construção de um conhecimento sobre a ciência em diferentes esferas da sociedade. Analisamos alguns documentos que versavam sobre o fortalecimento da cultura científica ${ }^{2}$ e percebemos que os sentidos produzidos nesses discursos fazem parte de uma formação discursiva calcada na concepção de uma ciência utilitária e indispensável à constituição da cultura humana. O desenvolvimento e fortalecimento de tal cultura é foco de uma política mundial e é apresentado como necessário à superação das desigualdades sociais. No entanto, além da defasagem no ensino de ciências, outros fatores dessa desigualdade têm peso igual ou superior no processo, e a articulação deles com a educação científica deve começar a ser discutida. Os debates em torno da divulgação científica atrelam-se, desse modo, aos aspectos educacionais (OLIVEIRA, 2011).

No Brasil, Massarani e Moreira (2004) mostram como houve, nas primeiras décadas do século XX, uma ambiência para o debate em torno da divulgação científica, que tinha relação com um grupo de intelectuais e cientistas que objetivavam a valorização da pesquisa básica. Para tal, a estratégia necessária era o aprimoramento do sistema educacional, com a criação de faculdades de Ciências e Letras que permitiram a formação de cientistas puros. Focalizando a participação de Miguel Ozório de Almeida (um dos assessores do Ince) nesse processo, os autores mostram sua perspectiva com relação ao papel da divulgação: ela traria tanto a familiaridade com a ciência quanto a confiança nos seus métodos e nos serviços que ela pode prestar.

Por colocarmos essa discussão no âmbito das mídias, especificamente do cinema como indústria e como projeto, lembramos, segundo Schvarzman (2004), que o cinema no Brasil começa a se consolidar como espaço de produção em virtude da sua utilização como veículo de propaganda e 
de projetos educativos por parte da política oficial. No campo da educação e da comunicação, são vários os estudos que mostram que data do início do século XX essa perspectiva de uso do cinema educativo em projetos de transformação social. Assim, procuramos apresentar um panorama desta perspectiva, para conduzir, posteriormente, as análises sobre a produção escolhida.

Partimos da Decreto n. 21.240, de abril de 1932, fruto de um estudo conduzido por solicitação governamental, tendo em Roquette-Pinto um dos seus idealizadores; ele que será um dos nomes do Ince e signatário do Manifesto da Escola Nova. Para o pensador, o Brasil e o governo de Getúlio Vargas teriam conseguido dar um passo decisivo em direção ao aproveitamento do cinema no âmbito da educação. A Lei, ao tratar do serviço de censura aos filmes, criava, também, as taxas cinematográficas que se voltariam à educação popular. Posteriormente, a taxa financiaria a criação e manutenção de um Instituto Cinematográfico Educativo. Havia, ainda, o projeto de organização de uma filmoteca e a publicação de uma revista de popularização da ciência (GALVÃO, 2004; DUARTE, 2004).

Segundo Galvão (2004), com esse Decreto dois direcionamentos se destacam. O primeiro elegia o documentário (científico, histórico, artístico, literário ou industrial) como um elemento fundamental para instrução pública e propaganda nacional. O segundo diz respeito ao estatuto dos filmes educativos, que passaram a ser considerados materiais de ensino, considerando, sobretudo, a vantagem que eles possuíam na instrução das grandes massas e dos analfabetos. "Foi também graças a essa lei que muitos filmes nacionais puderam ser produzidos com a aquisição de novos aparelhos, a indústria exibidora teve o seu desenvolvimento facilitado e foi incrementado o número de salas de exibição no país" (GALVÃO, op. cit., p. 46).

O Ince foi criado em 1936 e parou de funcionar em 1966. Sob influência do movimento no campo da educação, que preconizava o uso do produto fílmico nas atividades educacionais e com base no Decreto n. 21.240 de 1932, Roquette-Pinto elaborou o projeto de lei que viria a organizar este órgão, cujo objetivo era o de promover e orientar a utilização do cinema como auxiliar de ensino, adotando-o como instrumento voltado para a educação popular.

Tendo sido o primeiro órgão estatal brasileiro a considerar a importância do cinema nos processos educativos, o Ince se constituiu em um dos pilares do amplo projeto nacionalista brasileiro e, também, em um dos pontos de culminância do projeto de um grupo de educadores que observava 
Representaçôes imagéticas do fazer científico no contexto do Instituto Nacional...

a potencialidade desse novo meio de comunicação. Nesse grupo, incluíam-se nomes do movimento escolanovista como Anísio Teixeira, Fernando de Azevedo e Francisco Venâncio Filho.

Como aponta Catelli (2009, p. 6), Fernando de Azevedo, nos anos de 1920, foi um dos defensores do uso do filme no ensino, assim como do rádio, tanto por conta do número de analfabetos quanto pelo poder de sugestão dessas mídias, apoiado na ideia já consolidada sobre a comunicação como fator de integração das sociedades e na metáfora da sociedade como um organismo, também presente entre os idealizadores do cinema educativo, passando pela questão da "mistura" de "sangue novo" (dos imigrantes) para a formação da nação, nas palavras de Roquette-Pinto.

Segundo Vidal (1994), o ideário dos pensadores do movimento escolanovista preconizava a observação como uma das principais atividades pedagógicas. Assim, contrariando o ensino verbalista baseado nos processos de memorização, o movimento investia na compreensão dos processos e dos fatos, realçando, desse modo, as práticas de laboratório. "De auditório, a escola tornava-se laboratório. Passava a imperar o experimentalismo. Nessa concepção de ensino, destacava-se, principalmente, a Física, como redentora de um novo universo, e o laboratório como locus privilegiado para sua percepção" (VIDAL, op. cit., p. 25). Para Venâncio Filho, por exemplo, a Física era a disciplina auxiliar tanto para a Psicologia Experimental quanto para a Pedagogia, por conta do uso do laboratório como espaço de experiências e comprovação. $\mathrm{O}$ movimento tinha no discurso científico o apoio para a escolha dos métodos e da forma de atuação, construindo um "campo de legitimação para enunciados educacionais" (ibid.). A ideia de transformação estava presente em um contexto de mudança acelerada no campo social e econômico-industrial. Assim, o cotidiano era sentido como fruto de transformações incessantes, o que demandava uma concepção educativa que preparasse a criança para esse novo mundo, para essa sociedade em transformação.

A Física, com todos os elementos que agrega (cientista e laboratório), o cotidiano e o cinema encontram-se na proposta educacional de transformação. A proposta do uso educativo do cinema no Brasil nos anos de 1920 está impregnada da questão da Modernidade: "O cinema é um artifício, uma 'arma' moderna, portadora e transmissora da modernidade" (SCHVARZMAN, 2004, p. 18).

Havia, nesse sentido, duas posições. Diversos discursos de profissionais da educação apontavam para o potencial do uso do filme em sala de 
aula, ressaltando, porém, a influência negativa dos filmes de ficção. Mais do que uma diferença de gênero, esse discurso apontava para a valorização de um tipo específico de produção: aquela que se construía para fins educativos. O potencial para propaganda também era ressaltado, o que estava em consonância com políticas de outros países, como a antiga URSS e a Alemanha. Mesmo os EUA, aos quais usualmente atribui-se somente a produção de filmes comerciais, tratavam seus filmes como potenciais produtos comerciais e propagandísticos. Assim, eram necessárias produções que pudessem funcionar no processo de cooptação, de convencimento e de informação acerca da nova perspectiva educacional. No entanto, como toda essa estratégia tinha como foco não somente a população escolar, mas, também, toda a sociedade, a importação de filmes não era suficiente, ou mesmo apropriada, gerando a necessidade de uma produção nacional. Como exemplo desse momento, Vidal (1994) fala do filme Educação e trabalho, realizado em 1929 pela Botelho Film, sob a orientação de técnicos da Diretoria de Instrução do Rio de Janeiro, com o objetivo de difundir o ensino profissionalizante. Nesse contexto, que compreende as décadas de 1920 e 1930, amplos debates tomavam a produção fílmica como objeto de debate no âmbito da educação. Segundo Carvalhal (2008), o Ince teria sido resultado de grandes tensões e articulações políticas, educacionais, religiosas e culturais ao longo desse período.

Considerando a perspectiva atual de entrelaçamento entre cultura científica e alfabetização científica, o Ince emerge, nessa visão retrospectiva, como uma instituição cuja missão se coaduna com a perspectiva de uma educação científica ampla. Segundo Galvão (2004), de 1936 a 1966 ele cuidou de cumprir tal objetivo. A produção do Ince pode ser dividida em dois períodos: a primeira compreende seus primeiros dez anos; a segunda tem início em 1947, com a aposentadoria de Roquette-Pinto, e vai até 1966. Se, no primeiro momento, prevalecem os filmes de documentação de pesquisas científicas, no segundo, tem-se a criação de Humberto Mauro.

Além de contar com a expertise de um cineasta, o Ince estava bem aparelhado, possibilitando outros tipos de produção além da educativa, como documentários sobre a atividade nacional em muitos setores e o registro do trabalho de pesquisadores. O filme educativo no Brasil teve importante papel na divulgação, segundo Ramos (2000, apud GALVÃO, 2004), especialmente aqueles produzidos em 16 milímetros, mais baratos que os de 35 milímetros. Nesse contexto, o Ince foi fundamental no desenvolvimento de uma modalidade específica: o filme científico estatal. O Instituto, além 
Representaçôes imagéticas do fazer científico no contexto do Instituto Nacional...

de produzir, adquiria filmes feitos no exterior, a partir da avaliação de uma comissão de professores responsáveis pela seleção das produções estrangeiras. Segundo o professor Sylvio Valle Amaral, os critérios adotados para tal seleção eram o conteúdo e a técnica cinematográfica (GALVÃO, 2004).

No contexto do Ince, Galvão (2004) destaca o papel de divulgador de Roquette-Pinto, ao passo que Schvarzman (2004) indica ter sido ele um conhecedor profundo das teorias científicas dos campos pelos quais passou (da medicina à fisiologia, antropologia, etnografia), além de desejar aliar o conhecimento científico às possibilidades concretas de ação, para assim superar a miséria e o atraso social e econômico. De Humberto Mauro, Galvão (2004, p. 84) afirma que, além de ter "aproximado sua câmera dos operários ou de temáticas engajadas durante o Ciclo de Cataguases, ele também revelou o universo da ciência ao aproximá-la do laboratório, da bancada, da instituição ou da natureza”. Carvalhal assinala que, após uma intensa produção, no período de 1962 a 1964, Humberto Mauro produziu apenas um documentário: $A$ velha a fiar. Não havendo informações precisas sobre o motivo da queda de produção, especula-se, considerando seu caráter centralizador, sobre sua insatisfação com os novos rumos do Ince e com a participação de outras pessoas na produção documental. Finalmente, tem-se o nome de Jurandy Noronha, personagem que se destaca pela sua preocupação com a memória do cinema brasileiro.

Antes de apresentarmos as análises, cabem algumas observações sobre a produção dos documentários do Ince. Carvalhal (2008) indica que, no mapeamento feito por Carlos Roberto Souza, em 1990, a partir do Livro de Tombo do Ince, foram identificados 407 documentários, sendo 220 oficialmente atribuídos a Humberto Mauro. Há outros 123 títulos sem indicação de direção, constando, somente, o diretor de fotografia. Galvão (2004) também trabalha com o número de 407 produções, mas indica o problema de mapeamento, afirmando que há uma produção que não conta do catálogo de Carlos Roberto Souza, mas é apresentada como sendo do Ince na Enciclopédia do Cinema Brasileiro, e uma produção atribuída à Jurandy Noronha teria sido adquirida pela Kinarte, apesar de ao final do filme aparecer a informação Ince - 1964. Sheila Schvarzman, em sua tese, listou 358 filmes de Humberto Mauro, porque considerou os títulos sem direção como sendo do cineasta. Carvalhal, entretanto, contabilizou 353. Além disso, muitos títulos atribuídos a Humberto Mauro, na verdade, só foram reaproveitados pelo cineasta. 


\section{O oxigênio - natureza e tecnologia}

Produção de 1958 (17min46seg) é classificada como de divulgação técnica e científica. Os créditos iniciais não apresentam o nome de Humberto Mauro, mas a ficha técnica da Cinemateca Brasileira informa ser um filme dirigido por ele. Os créditos iniciais indicam a orientação científica do professor Alcides Silva Jardim, da Universidade do Brasil, que também participa do filme, segundo a ficha técnica.

De início, temos a presença de uma voz over ${ }^{3}$ que traz todas as informaçôes importantes para o público acerca do oxigênio. Seguem-se descriçōes sobre a composição do oxigênio, onde ele é encontrado e com quais outras substâncias ele faz combinaçōes. Tal narrativa é acompanhada por imagens de campos, rios e cachoeiras. O papel do oxigênio da fotossíntese entrelaça-se com o discurso sobre a importância do reflorestamento. Há a utilizaçâao de esquema animado para apresentar o processo de obtenção do oxigênio pelo fracionamento do ar liquefeito. Esse momento funciona para introduzir a produção de oxigênio pela indústria brasileira, que é feita em larga escala, graças a uma aparelhagem moderna e de alta precisão, narrativa acompanhada por sequências de homens trabalhando nesse processo. Conforme nossas análises, entendemos que estas sequências configuram uma parte introdutória e dura cerca de quatro minutos, com cenas externas e dois momentos explicativos: o do símbolo do oxigênio e do esquema do processo já citado. Denominamos essa parte do filme contextualização, por funcionar como contexto ao tema do documentário, o oxigênio, e por apresentar alguns elementos que serão retomados mais adiante.

Após esse momento, inicia-se o que indicamos como segmento experimental, com cerca de dez minutos. A passagem ocorre quando é fornecida uma informação sobre experiências laboratoriais, mostrando determinadas características do oxigênio. Essa parte é toda encenada no laboratório, com a presença do dr. Alcides Jardim e sua auxiliar, ambos de roupa branca. Cada experimento é narrado pela voz over e a câmara focaliza sempre em plano americano o pesquisador e sua auxiliar e em closes os equipamentos e as mãos de ambos durante o processo de manuseio dos instrumentos. Várias experiências são realizadas.

Finalmente, temos a terceira e última parte, consolidação, onde retornam as cenas externas com encenaçóes em diferentes espaços, nos quais o oxigênio pode apresentar uma funcionalidade. Tem-se, assim, a importância 
Representaçôes imagéticas do fazer científico no contexto do Instituto Nacional...

do oxigênio para as atividades físicas, incluindo mergulho; cenas de corrida seguidas de recuperação de uma corredora com o uso do balão de oxigênio; uma sequência de pesca submarina, indo desde a preparação do tanque de oxigênio até o peixe arpoado. Uma sequência mostra o armazenamento do oxigênio nos submarinos, focalizando uma embarcação brasileira. Após o submarino nacional ser enquadrado singrando o mar, vêm cenas mostrando aviōes da força aérea brasileira no solo e pilotos embarcando. A voz over, então, informa que graças ao oxigênio puro é possível aos pilotos dos aviões a jato voarem cada vez mais alto, em uma narrativa embalada por $A$ cavalgada das Valquírias, de Richard Wagner. Tal sequência termina e tem início uma explicação simples e didática sobre o uso do oxigênio na propulsão dos foguetes interplanetários (algo que a própria autora do trabalho desconhecia e aprendeu durante as análises), por meio de um desenho esquemático mostrando a ação do combustível líquido e do combustível metálico. Segue-se a cena de lançamento de um foguete. $\mathrm{O}$ final apresenta um foguete rumo ao espaço.

\section{Os elementos da narrativa}

O filme constrói-se em três partes harmônicas: a contextualização do oxigênio abre para sua exploração no laboratório e daí para o mundo externo, foco da terceira e última parte.

A música acompanha todas as partes. Alguns teóricos da área de cinema afirmam que a forma musical é, em geral, determinada ou subordinada à forma narrativa, além de outras questóes como o momento em que ela entra ou sai das ações, fato que não deve acontecer simultaneamente à voz. Batista (2007, p. 34) cita diferentes estudos sobre a questão, sendo que é do nosso interesse, para situarmos a condição das composições neste documentário, a classificação de Claudia Gorbman. A partir do estudo da autora, a música funciona para determinar climas específicos, podendo funcionar como representante do sentimento épico. Nesse sentido, a música romântica com orquestração grandiosa estaria relacionada a esse aspecto do "sentimento épico". Assim, como afirma Batista (op. cit., p. 34-35), aliada ao visual "ela eleva a individualidade dos personagens para uma significância universal, os faz maior que a vida, sugere transcendência e destino”.

A costura entre a trilha sonora, os grandes planos panorâmicos e o encadeamento das três partes denotam a preocupação com a natureza argumentativa da proposta, ou seja, construir ambiência para uma explicação 
científica e, também, para uma propaganda de Estado, de modo mais claro nas sequências das forças armadas no mar e no ar.

Nas sequências do segmento experimental, podemos destacar os momentos nos quais o pesquisador trabalha com oxigênio líquido e a fumaça toma conta do cenário. Aí, a música atinge acordes mais altos, como em filmes de suspense e de ação, dando mais dramaticidade à cena. $\mathrm{O}$ mesmo acontece quando há momentos de experimentação com elementos explosivos. A presença da câmera fixa com mudanças de planos (plano americano e closes nos experimentos) configura essa fase do documentário.

A sequência dos experimentos laboratoriais parece funcionar, no meio da narrativa, para facilitar o entendimento da aplicabilidade do uso do oxigênio, que será o foco da terceira parte. Toda ação que se passa no espaço do laboratório remete aos predicados da observação e da perspectiva da cientificidade. O próprio arranjo espacial do laboratório - com a bancada, o quadro negro ao fundo com desenhos esquemáticos dos experimentos parece indicar um espaço do aprendizado prático e não da exposição verbal exaustiva que leva à simples memorização.

$\mathrm{Na}$ terceira e última parte, consolidação, destaca-se, mais uma vez, a valorização das cenas com a utilização da música. As explicações dadas pelo narrador em voz over não estão presentes em todas as sequências e há sempre momentos em que as imagens são acompanhadas somente pela trilha sonora, levando o espectador a aderir ao que está sendo mostrado: sequências de cachoeiras, aviōes no ar, a atividade do mergulhador. Percebemos que o uso dos recursos cinematográficos, principalmente nestas sequências, traz para a produção um elemento diferenciado, tendo em vista o destaque que o filme procura dar para a presença da substância oxigênio no nosso cotidiano. No entanto, esse cotidiano não é somente o da vida doméstica ou do mundo do trabalho; ele está relacionado ao contexto maior do progresso da nação. Junto às imagens e à música, a voz over, falando ao espectador, somente, enfatiza e reforça a mensagem de consolidação do avanço tecnológico. Isso pode ser visto na própria construção do filme, que "cresce" desde as cenas iniciais focalizando a natureza até o final com um foguete decolando para o espaço. Da natureza à tecnologia, sendo a segunda a atividade de controle e manipulação da primeira, pois o oxigênio (substância da natureza) funciona nesses espaços da tecnologia, na medida em que é trabalhado pelo homem.

Retomando algumas questôes apresentadas na parte inicial deste artigo e relacionadas ao ideário escolanovista, entendemos que toda ambientação 
Representaçôes imagéticas do fazer científico no contexto do Instituto Nacional...

e esforço narrativo estão voltados para a concretização de um aprendizado acerca da substância química, que procura não enfatizar fórmulas ou outros elementos mais presentes em livros didáticos, como a tabela periódica, por exemplo. Somente no início do filme é apresentado o símbolo do oxigênio e seu peso atômico. Durante o resto da produção, várias referências são feitas, inclusive o enfoque de preservação da natureza.

\section{Considerações parciais}

Krasilchick (1981) mostra como, no cenário dos anos de 1950, as ideias de mudança no ensino de ciências ainda provinham do manifesto da Escola Nova. Ela apresenta alguns pontos priorizados pelo movimento, destacando-se a inclusão, nos currículos da formação em nível superior, do que havia de mais moderno na ciência, de modo a formar profissionais que incrementariam o desenvolvimento industrial, científico e tecnológico; os métodos expositivos deveriam ser substituídos pelos métodos ativos, havendo preponderância do laboratório. Krasilchick destaca tais iniciativas no período de 1950, porém o próprio ideário do Ince já trazia um diálogo com a perspectiva escolanovista, o que nos leva a considerar que o filme analisado insere-se nessa corrente de fortalecimento da educação científica em diferentes esferas de formação e com a adoção de diferentes estratégias formativas.

Em $O$ oxigênio, assim como em Lições de Química I, filme por nós analisado em outro momento, o laboratório não é somente cenário, pois constitui, na nossa percepção, a representação metafórica do procedimento almejado de ensino aliado à ação, de negação dos procedimentos tradicionais. Nessa produção, a sua conjugação com cenas externas e explicações da aplicabilidade e presença do oxigênio em diferentes espaços do mundo do trabalho e indústria, inclusive militar, aponta para um contexto idealizado de compreensão social ampla das prerrogativas da ciência. $\mathrm{O}$ destaque não é somente do oxigênio, mas, também, da ciência, pois sua aplicabilidade é demonstrada assim como sua presença constante no nosso dia a dia e no progresso da nação. Do campo da ciência ao espaço do vivido, o oxigênio transita como leitmotiv para uma conjunção - desenvolvimento científicodesenvolvimento nacional - que só é possível por uma educação renovada.

Não há como responder a uma questão como O que é ser alfabetizado cientificamente? Mas é possível compreender os esforços oficiais no sentido 
da consolidação de uma cultura científica. Quando estas expressões ainda não circulavam no espaço midiático, os esforços dessas figuras proeminentes consideravam a pertinência de se saber mais sobre a ciência, levando em conta um contexto maior de desenvolvimento tecnológico e de crescimento econômico, e compreendiam o papel fundamental de uma educação não conteudista nesse empreendimento.

Também não estava em pauta uma percepção da ciência como fazer cultural, tendo em vista o valor que lhe atribuíam como saber privilegiado e a não presença de discussões polêmicas sobre o fazer científico. No entanto, é possível perceber que, ao procurar educar cientificamente, todos esses esforços iam em direção da formação de uma tradição científica necessária ao crescimento do país.

Esse encadeamento sequencial educação-ciência-progresso era um fato naturalizado nos discursos que sustentaram as iniciativas aqui elencadas e que fomentaram diferentes instituições e dispositivos de divulgação científica.

Elementos variados estão atrelados a este encadeamento, destacando-se aqueles já assinalados por alguns escolanovistas: a percepção da Física com sua estrutura experimental e o uso do laboratório como índice do fazer apropriado a esse novo contexto que se deseja consolidar; a ideia de aceleração nos campos sociais e econômicos, levando à sensação de transformação que deve ser acompanhada por uma nova educação; a divulgação científica sendo focalizada como elemento principal nos processos de educação científica.

Estes elementos não funcionam somente para situar os filmes do Ince em uma problematização restrita à relação cinema e educação. Eles também apontam para a nova condição desses filmes como documentos de memória da ciência no Brasil, considerando o que eles trazem do período de elaboração e como eles referenciam os projetos da época. As representações que se consolidam nessas narrativas, e que apontamos no filme analisado, possuem tonalidades diferenciadas face à própria trajetória do Ince. No entanto, elas oferecem, mediante perspectiva analítico-crítica, uma janela para o modo de se pensar a educação, a ciência e o desenvolvimento durante três décadas de marcante diferença no cenário político-ideológico do Brasil.

Nesse sentido, nossas investigações indicam essa relação com discursos e posicionamentos ideológicos cientificistas que sustentam, até a contemporaneidade, a positividade da ciência e sua força na construção de novas soluções para os problemas mundiais. Assim, apesar da diferenciação com relação a essa posição positivada, pois hoje as questôes polêmicas da ciência são colocadas de 
Representaçôes imagéticas do fazer científico no contexto do Instituto Nacional...

modo mais firme e consistente, esse campo continua seu trabalho hegemônico, elaborando, agora, as soluções para os problemas oriundos de sua antiga e contínua relação com a tecnologia e avanço econômico.

Discutir esses documentários, assim como outros tipos de produçôes fílmicas, é considerar como se coloca em perspectiva uma relação sobre a qual ainda temos muito a problematizar: o mundo imagético e a educação.

\section{Notas}

1. Sobre Doyen há uma história curiosa. Alguns de seus filmes sobre cirurgias foram parar nas mãos de alguns produtores, incluindo os irmãos Pathé, que reeditaram cenas em filmagens que percorreram alguns lugares da Europa, em sessōes para "pessoas ávidas de emoçōes fortes". O caso foi a julgamento e o cirurgião foi reconhecido como único dono das imagens, sendo os outros obrigados a pagar pesadas multas. No período, última década do século XIX, as discussōes sobre a produção e uso das imagens eram raras, principalmente no âmbito jurídico.

2. Analisamos os artigos que compõem o livro Cultura científica: um direito de todos (SASSON et al., 2003), que consiste em "uma contribuição da Unesco para um momento estratégico da educação brasileira", segundo seu editor Jorge Werthein. Outros documentos estão em fase de análise e as consideraçōes aqui apresentadas valem para este documento.

3. Segundo Ismail Xavier, voz over é aquela que fala com o espectador, diferente da voz off que está presente no filme, mas fala com as personagens (ARMANI, 2010).

\section{Referências}

ARMANI, P. Ismail Xavier. 2010. Disponível em: <http://www.priscilaarmani. com.br/296-296/>. Acesso em: 6 jun. 2011.

BAPTISTA, A. Funçóes da música no cinema: contribuições para a elaboração de estratégias composicionais. 2007. 174f. Dissertação (Mestrado em Música) - Escola de Música, Universidade Federal de Minas Gerais, Belo Horizonte. Disponível em: <http://www.musica.ufmg.br/sfreire/depot/ DISSANDREBAPT.pdf>. Acesso em: 5 abr. 2011.

BRASIL. Decreto n. 21.240, de 4 de abril de 1932. Nacionalizar o serviço de censura dos filmes cinematográficos, cria a taxa cinematográfica para a educação... Diário Oficial, Rio de Janeiro, 12 ago. 1932.

CAPRIA, M.M. Introdução: a ciência e a imagem do mundo. In: CAPRIA, M.M. A construção da imagem científica do mundo. São Leopoldo: Unisinos, 2004. p. 13-50. 
CARVALHAL, F.C.A. Luz, câmera, educação!: o Instituto Nacional de Cinema Educativo e a formação da cultura áudio-imagética escolar. 2008. 311f. Dissertação (Mestrado em Educação) - Curso de Pós-Graduação em Educação, Gestão e Difusão de Ciências, Universidade Estácio de Sá, Rio de Janeiro. Disponível em: <http://www.dominiopublico.gov.br/download/ texto/cp066409.pdf>. Acesso em: 5 set. 2011.

CATELLI, R.E. O Instituto Nacional de Cinema Educativo: o cinema como meio de comunicação e educação. 2009. Disponível em: <http://www2. eptic.com.br/sgw/data/bib/artigos/b2d62f74fa61d243a02f4e4f8a3ce8c2. pdf>. Acesso em: 8 abr. 2011.

CHASSOT, A. Alfabetização científica: uma possibilidade para a inclusão social. Revista Brasileira de Educação, Rio de Janeiro, n. 22, p. 89-90, jan./ abr. 2003.

DUARTE, R.H. Em todos os lares, o conforto moral da ciência e da arte: a Revista Nacional de Educação e a divulgação científica no Brasil (1932-34). História, Ciências, Saúde, Manguinhos, v. 11, n. 1, p. 33-56, jan./abr. 2004.

DURANT, J. O que é alfabetização científica? In: MASSARANI, L.; TURNEY, J.; MOREIRA, I.C. Terra incógnita. Rio de Janeiro: Vieira e Lent; UFRJ; Casa da Ciência; Fiocruz, 2005. p 13-26

EPSTEIN, I. Divulgação cientifica: 96 verbetes. São Paulo: Pontes, 2002. GALVÃO, E. A ciência vai ao cinema: uma análise de filmes educativos e de divulgação científica do Instituto Nacional do Cinema Educativo (Ince). 2004. 278f. Dissertação (Mestrado em Ciências) -Departamento de Instituto de Ciências Biomédicas, Universidade Federal do Rio de Janeiro, Rio de Janeiro.

KRASILCHIK, M. O professor e o currículo das ciências. São Paulo: Edusp, 1981.

LEFEBVRE, L. Le docteur Doyen, un précurseur. In: MALLASINET, A. (Org.). Le cinema et la science. Paris: CNRS, 1994. p. 70-77.

MASSARANI, L.; MOREIRA, I.C. Miguel Ozorio de Almeida e a vulgarização do saber. História, Ciências, Saúde, Manguinhos, v. 11, n. 2, p. 501-513, maio/ago. 2004. 
Representaçôes imagéticas do fazer científico no contexto do Instituto Nacional...

MORA, A.M.S. A divulgação da ciência como literatura. Rio de Janeiro: Casa da Ciência; UFRJ, 2003.

O’GOMES, I. L'ouvre de Jean Comandon. In: MALLASINET, A. (Org.). Le cinema et la science. Paris: CNRS, 1994. p. 78-85.

OLIVEIRA, C.I.C. Os discursos sobre a cultura científica e a afirmação da ciência como saber. In: SEMINÁRIO BRASILEIRO DE ESTUDOS CULTURAIS E EDUCAÇÃO, 4., 2011, Canoas. Anais... Canoas: Ulbra, 2011. v. 1, p. 1-14. (CD-ROM).

RAMOS, F.; MIRANDA, L.F. Enciclopédia do Cinema Brasileiro. São Paulo: Senac, 2000.

SASSON, A. et al. Cultura cientifica: um direito de todos. Brasília, DF: Unesco, 2003.

SCHVARZMAN, S. Humberto Mauro e as imagens do Brasil. São Paulo: Unesp, 2004.

VIDAL, D.G. Cinema, laboratórios, ciências físicas e escola nova. Cadernos de Pesquisa, São Paulo, n. 89, p. 24-28, 1994. Disponível em: $<$ http://www.fcc.org.br/pesquisa/actions.actionsEdicoes.BuscaUnica. do? codigo=794\&tp_caderno=0 $>$. Acesso em: 3 set. 2011 .

Recebido em 12 de maio de 2013.

Aprovado em 11 de outubro de 2013. 